\title{
The Marginalized Representation of the Bond's Girls in Selected James Bond Movies
}

\author{
Tjioe Vincent. $\mathrm{H}$ \\ English Department, Faculty of Letters, Petra Christian University, Siwalankerto 121 - 131, Surabaya 60236, East \\ Java, INDONESIA \\ E-mail: m11413037@john.petra.ac.id
}

\begin{abstract}
In James Bond movies, there is a formula that becomes the characteristics of the movies. This formula is the pinnacle/basic story plot of the James Bond series. In all of the movies, there are always what so-called Bond's girls. The Bond's girls cannot be separated from the plot as they are one of the most famous features of the movies, besides the advance gadget. The Bond's girls are the formula of the Bond series. They always appear to help James Bond during his duties. Although their roles are always helping James Bond, it often happens that James Bond saves them instead. This attract my attention in analyzing why, in James Bond series, women are represented in such a marginalized way despite their pivotal role. Through my analysis on the four latest James Bond series, I want to reveal the reason behind the marginalized representation of women in James Bond movies. In the analysis, by using theory of representation and encoding/decoding, I find out that they are being poorly, as well as intentionally and marginally represented. They are often sexually objectified. My findings show that the Bond's girls are represented as dependent, semi strong/ignorant, sexual object, and weak/damsel. These traits are the reflection of how the society views women. Through that kind of representation, James Bond becomes the center of attention. He appears as a better hero because of the Bond's girls, that is, he saves them all whenever they are in troubles.
\end{abstract}

Key words: Representation, decoding, Bond's girls, marginalized, diverse cultural

The James Bonds series were created by Ian Fleming, an English author, journalist and naval intelligence office. The popularity of James Bond leads to the adaptation of this character for television, radio, comic strip, video games and film. The most famous adaptation is the film series, which are the longest continually running and the third-highest-grossing film series to date. Among the many version of James Bond movie series, I am interested in the Craig versions, that is, the series starred by Daniel Craig. The story of James Bond always goes by a formula, common threads that run through most of the films, first, the story usually takes place in different country where James Bond is doing his job, spying someone, which later brings him to the villain and later action of chasing and shooting happens and ended with a gun barrel sequence and title sequence. The narrative structure of these formula represents a modern variation on the universal theme of the struggle between good and evil. The story involve a transformation of the basic elements between good and evil. They express a universal structure of basic oppositions (Strinati, 2004).

As you can see in all of Bond's movies, there are always this other characters, and they are always girls, these girls are they refer to as "Bond's girl's", presenting as the James bond's side chick or sidekick (Adams, 2003). She is as indispensable as the gadgets, the car, the chase and the villain set on overtaking the earth. They have always been in the centre of controversy; they have always been branded as beautiful women who need Bond and ironically, Bond cannot complete his mission without them. Imagine if these roles or the Bond's girls are not present with the formula, it will not make James Bond as good as we think he is, a great spy. The roles of these Bond's girls are very important and have pivotal roles to the story plot in the each of the Series and the Bond's girls are actually the ones that helps Bond in tight situation or in finding information about the enemy. On one hand the roles of the girls are important, as they appear as sidekicks because it is one of the characteristics of the Films' formula but actually the role of the girls are marginalized. Being marginalized means that although they have a strong role, such as the sidekick of James Bond, in the narrative, they do not appear fully as the sidekicks. 
Instead, they are depicted as something else, whose roles are entirely different from those of the sidekick. This triggers a question, that is, if the girls' roles are important, why are they depicted in a marginalized way? They appear to help Bond with his mission, they have roles that are pivotal to the mission but ends up being marginalized as Bond keeps rescuing them. That is why I am interested in analyzing the marginalized representation of the Bond girls in selected Bond's Movies.

I would like to analyze why, in James Bond four latest series, women are represented in such a marginalized way despite their pivotal roles. I want to reveal the reasons behind the marginalized representation of women in James Bond movies. In doing so, in this project, I am going to use cultural approach, the theory I use in this approach is theory of representation and Encoding/decoding. These theories combine to shape my understanding of the views on women in the Bond movies are constructed in a culture and in visual ways. In the following section, I address the ways these frameworks and theories guide this project.

First, I am going to explain what representation is and how it can help me in analyzing my work. The concept of representation has come to occupy a new and important place in the study of culture. Representation is the act of presenting something or somebody in a particular way, or something that shows or describe something. In representation, according to Barker, there is a semiotic process. He writes that representation refers to "a set of processes by which signifying practices appear to stand for or depict another object or practice in the 'real' world" (Barker, 2004, p.177). So, representation is not just the act of presenting something or somebody, but there is a process that ascribes meaning to the object it represents. Here, people can see that the meaning which representation generates is dependent upon culture. Since representations are not innocent reflections of the real but cultural constructions, it could be otherwise more than what they appear. It occurs because representations, according to Barker, "are constitutive of the meaning of that which they purport to stand in for" (Barker, 2004, p.177). Thus, in representations, there is no direct relation between the sign and the object it represents because of the cultural or ideological involvement in the semiotic process in representation.

Representation in a cultural text does not exist in a vacuum. Representation is influenced by the social norms and values in the society. Thus, the acts of representation are framed in a particular way and given a particular meaning depending on how representation is coded. That is why besides the theory of representation I also use the theory of Encoding/decoding. Stuart Hall defines encoding as "selecting the codes which assign meaning to events" (Miller \& Jeremy, 2012), while decoding assigns meaning to the message that may or may not agree with the intended meaning that was encoded into the message. That means, when individuals watch a movie, they interpret the movie by their own understanding which is influenced by their cultural knowledge and experiences. In this way, they create new meanings of the movie they watch. Using Hall's encoding/decoding theory, I analyze how female representation in James Bond movies sends a particular message, that is, about the marginalization of women.

In analyzing the representations of the female main characters, I need to understand the ideological and cultural context of how women are seen because the message of representation cannot be separated from the contexts of the society where the text exist. Ideology refers to a set of ideas which produces a partial and selective view of reality. Barker writes that "ideology is grasped as ideas, meanings and practices which, while they purport to be universal truths, are maps of meaning that support the power of particular social classes" (2004, p.97). He writes further that "Ideology is not separate from the practical activities of life but provides people with rules of practical conduct and moral behavior rooted in day-to-day conditions" (2004, p.97). Thus, ideology is created by the practices and experiences of the society. The notion of ideology entails widely held ideas or beliefs which are seen as common sense and become naturalized, so, if such activities frequently happens, it will make an ideology stronger and if less frequent will be known as against that particular ideology. The stronger the belief is, the more likely people decode messages as they see fit with their beliefs. The weaker the beliefs is, the more likely people are against those beliefs.

Besides the system of patriarchy, gender stereotype also plays a role in shaping how men view women. Gender stereotype is a belief about the psychological nature and characteristics of men or women. Therefore, stereotyping affects very much on how people see women. There is a tendency that 
men, rather than women, are depicted as the strong dominant ones. This happens because of how cultural context where man must work and women as the supportive ones, as what Brannon (2017) calls as the Cult of Womanhood. Gender stereotyping is also seen in the movies.

To sum up, in the analysis, first of all, by using characterization, I analyze how the female main characters in James Bond movies are characterized. After I get the idea of how they are depicted, I am going to find out why the women are represented in those ways. The theory of representation helps me to understand the representation of the female main characters in the movies. In applying this theory, first of all, I find out the depiction of the Bond's girls, namely, how they appear in the beginning and how they appear late; whether their appearance is consistent with the given role or whether they experience marginalization in the narratives. The patriarchal ideology and the gender stereotype help me analyze the Bond's girls that is, how they are being represented, whether they are treated marginally like women in the societies where patriarchal ideology is pervasive, or where they are stereotypically judged. I use encoding/decoding theory to understand or to find out the meaning behind the marginalized representation. I apply this theory when I get that the Bond's girls are being represented marginally and try to decode why must the Bond's girls experienced marginalization, is there any reason to it.

\section{REPRESENTATION OF BOND'S GIRLS IN SELECTED BOND MOVIES}

\section{The Representation of the Bond's girls as Dependent women}

One girl that is represented in a marginalized way, namely, changing from being independent to being dependent, is Madeleine, the Bond's girl from Spectre. She is represented as an independent woman because she can work for herself for a living, as a doctor. In the scene where she first appears, she is working in an expensive place as a doctor, this shows that she is independent as she appear as someone who can work for themselves. Her independence can be seen from her attitude as professionals in the following scene as she doing a recording with foreign language and also the English conversation she have with Bond.

Madeleine: My name is Dr. Madeleine Swann. I going to ask you some question. Do you exercise?

Bond: $\quad$ When I have to.

Madeleine: Do you consider you work to be physiological stressful?

Bond: $\quad$ Sometimes

Madeleine: How much alcohol do you consume?

Bond: $\quad$ Too much

From her questions, we can see her independence as she knows what she is doing as a professional doctor. After Bond leaves her alone in her office a group of people kidnap her. Although she shows her resistance, she cannot save herself. It is James Bond that later on rescues her. From this scene, her independence fades away as she cannot fight from the kidnappers and that she needs help as she sits quietly in the car. Her being independent does not includes independent in protecting herself. That is why Bond comes to save her. Now, from the first time she appears, she is represented as someone independent as she can work for herself, but then represented unable to protect herself in combat. She experienced marginalization in the narrative where she is kidnaped and cannot fight back and Bond has to come and rescue her. The way I decode the roles of Vesper and Madeleine shows that the movie depicts Vesper and Madeleine in a marginalized way. Although they are both independent people, when they are with Bond, they experience subordination. Bond as a man is described as superior to them. The narrative encodes the patriarchal ideology in the movie. This results in putting the Bond girls in such a way that they are unable to do anything. Their independence changes into dependence when they are with Bond. Bond is described as a man who has higher power than women. This is reflected in the plot of the story when Bond keeps on helping them. Thus, this situation makes James Bond the hero as well as the center of women's attention.

\section{The Representation of the girls as Weak}

Vesper in Casino Royale is one proof of such a women. She is characterized as independent and intelligent woman, as seen in the narrative where she helps James Bond with his mission to take 
down the enemy but despite all that she is also being forced to represent as a weak woman. In the scene, where Vesper and Bond are ambushed by the Nigerian in Casino Royale, Vesper is unable to fight back as she struggles to run away. From this depiction, Vesper is shown very fragile as she really struggle to break free from being murdered. She could not do anything, she needs Bond to help her, as she is being hit. She struggles to run away and she also struggles when she is trying to help Bond when Bond is being pushed. This scene represent Vesper as a weak woman as her weak point is shown as she cannot fight the enemy and can only run away. Her weak representation is clear when she was showering, because of the enemy's blood she becomes very traumatic towards that event.

The way I decode the roles of Vesper shows that the movie depicts Vesper in a marginalized way, she is first appear professionals in her work but then she is brought to a scene where nothing is related to her job, which is fighting. The events where she fights is the proof of her marginalized way because it exploits her weakness. Even though Vesper is independent and intelligent, she is depicted as a weak person. I find that the narratives encodes Vesper with gender stereotype by making her weak, as Bond can come to the rescue and be the hero. With the representations as such, she looks so weak and vulnerable that Bond has to come and help her. The representation of weak women like this reinforces Bond's character traits as a strong man.

\section{The Representation of the girls as Damsel or Sexually Objectified}

One of the proof is Solange. She is the Bond's girl in Casino Royale. Bond has to seduce her to get information about her boyfriend which is a friend of the enemy. Solange acts only as one of the enemy's girlfriends, she is depicted as a submissive/subordination person. During the poker night scene, she approach her boyfriend but getting yelled at for being late.

$\begin{array}{ll}\text { Solange: } & \mathrm{Hi} \\ \text { Man : } & \text { If that was for luck } \\ & \text { You are two hours late }\end{array}$

Through this dialogue, it can be seen that she is being treated badly by the man, then James Bond approach her and offer her a drink at Bond's place, it was easy for her to say yes, this can also shows how she missed being treated good by someone. Solange might be shown as Bond's lover, but she has a boyfriend, so I depict that Solange is a woman who wants to have fun since she is being treated badly by her lovers. Bond uses her loneliness to have sex with her and then Bond asks her about the enemy information only for a night with Bond. The next time Bond see her, she has died horribly. In this scene, I find that she is being oppressed by her lover thus she is also being represented as a damsel, as Sultana Mention "Subordination is the situation in which one is forced to stay under the control of other. So women's subordination means the social situation in which women are forced to stay under the control of men" (Sultana, 2011, p. 8). Again, she is represented as a sex object, as she dies after being seduced by Bond, because of that she has been labeled as a subordinate to men, as she is not loyal to the man who subordinate her.

These girls are portrayed marginally through their representation as damsels in distress because they always appear to be the wives of bad people. These bad people treats them badly and Bond had to seduce them to gain information. They were actually pictured as snitches. That is why Bond always gets to them first to gain information. The formula already marginalized them so that the plot can happens where Bond seduce them for information and with their background that help them to be in need a night with Bond.

\section{The Representation of the girls as Incapable}

The girl is Moneypenny from Skyfall, she is also a field agent of MI6 intelligent. In Skyfall, at the beginning at the scene, she was with Bond doing a mission together. Moneypenny is shown very strong, brawn, independent woman because she could fight, drive, shoot guns and have occupations as an operative field agents. During a car chase scene, it could be seen how good she was until one moment when she has to shoot the enemy while fighting Bond, she miss the shot and hit Bond instead. After all the representation of how strong she is, another representation shows that she was incapable in making action. Making mistakes even though she is a professional agent. Moneypenny is pictured 
lacking than men as they have been stereotype as women are lacking in many terms, in this case, is her action. She is represented as a strong women until the shooting scene, her representation changes that she is incapable.

Next, she appears again in the gambling place scene, she is there to help Bond in his Mission acting as a spy, but before that she shave Bond's beard, the idea is unrelated towards the mission, why must she act like a subordinate in the films.
Bond
: Raising the tantalizing question of what you're really doing here?
Moneypenny
: my official directive was to help in any way I can

In this scene and dialogue, she shows a caring side of her and also Bond knows that she is incompetent in doing her job. So, she tries to be competent as she know as well as Bond she is not as competent as Bond. This idea tells us men are more competent that women (Brannon, 2017). Moneypenny is also being represented as woman of patriarchy society where she acts accordingly to their head of the community (Sultana, 2011).

Monnypenny are the representation of women who are incapable of accomplishing their missions without the help of a man that is James Bond. In the narration, both of them are seen as fighting together with Bond. However, in the end, Bond has to help them. I decode that the reason they appears alongside each other during an action scene is to show how different they are in terms of level between men and women. Women tend to make mistakes and have to be covered by the men who is better than women.

\section{CONCLUSION}

So, my findings by using the theory of representation by Stuart Hall, I have found that actually the Girls of James Bond series are intentionally being represented marginalized through the scenes where there Bond's girls show up. The marginalized way is that first they appear as beautiful girls, some of them look independent, smart, and strong and some others look very charming. Based on my analysis, I also found out that every Bond's girls has always appear pretty since the first James Bond Movie. Then, with the plot. The plot make these girls to be put in a marginalized ways, such as, be put in places or actions as it exploit their weaknesses or vulnerabilities as it really shows where they cannot do anything when compared to James Bond himself. They will be put on, let say, juxtaposed with Bond as it will make a comparison between the Bond's girls and Bond himself. Another theory I used from the same theorist, Stuart Hall, is Encoding/Decoding. With this theory, I have found that the scenes have exploited their vulnerabilities and so the real representation of the Bond's girls will resurface as new and different Bond's girls. These exploitation will have some different views upon the Bond's girls as they will have another role beside the given role, for example, as Bond's partners or as Bond's lovers, which is, that their roles are to make James Bond look better than the girls and also to the enemy. The enemies are also being represented as bad men who treats the women badly, there is misogyny in these films and only James Bond who looks the only one who is sane, heroic and gentlemen towards the Bond's girls. Thus, the representation of the marginalized Bond's girls need to take place in the narrative. The narrative of James Bond happens with a formula of how James Bond have always appeared the whole time in the series from the beginning until the latest James Bond series. From being given an assignment to defeating the enemy, in that formula, there are always a term known as the Bond's girls and so these Bond's girls, based on my research or analysis, are just somewhat a tool to enhanced and enforced the Bond skills, ability, and so on. Because of the Bond's girls, James Bond can look twice the better hero or main character

In conclusion, James Bond are movies that introduce terms such as Bond's girls which are one of the formula of creating James Bond movie. These Bond's girls have always appear in all James Bond Movies from day one. The Bond's girls have a role in the movies as well but in my analysis I found out that the representation of the Bond's girls always appear marginalized as they being pictured badly enough by the movies in the narratives. So, in my analysis, I try to find out the meaning intended behind the representation of the Bond's girls. Later on, I found out, the girls are represented differently from each Bond's girls in the latest four movie that I am analyzing and in each Bond Movies there are always 
at least two Bond's girls appear in one movie. One is always independent and the other one always appear mistreated by their man of husband. Then, all of their representation changed as they appear in a situation where it will exploit their vulnerabilities, James Bond then appears to save the all from being mistreated and kidnaped or robed of their freedom. The marginalized happens when these girls appear as they cannot outdone the scene they are in, such as, when they cannot escape the enemy and so on, also the girls sometimes reflected the society views on women as they are weak, not smart then man in the movies. Then, James appears with these girls, let say, side to side, in this scene, I decode when they are in bad situation, Bond always appear as heroic than before, suddenly James Bond be hero all the Bond's girls need. He covers the exploited spot the marginalized women's representation. As if they were being compared to one each other, man will always appear better in actions or in intelligence. The marginalized ways of the Bond's girls is that, they are just bring used as another tool like the gadgets to empowered Bond, to make Bond appear as the greatest hero in the series.

\section{REFERENCES}

Adams, M. (2003). Bond Girls: GENDER, TECHNOLOGY AND FILM.

All Time Worldwide Box Office Grosses. (2017, February). Retrieved from Box Office Mojo.:

http://www.boxofficemojo.com/alltime/world/

Brannon, L. (2017). Gender: Psychological Perspectives, Seventh Edition. Routledge.

Goodman, S. (2015). British Spy Fiction and the End of Empire.

Gordon, \& Baxandall. (2002). A Companion to American Women's History.

Gordon, R. B. (n.d.). Second-wave Feminism.

Gürkan, H., \& Ozan, R. (2015). Feminist Cinema as Counter Cinema: Is Feminist Cinema Counter Cinema? Online Journal of Communication and Media Technologies.

Hall, S. (2013). The work of Representation.

Miller, \& Jeremy, R. (2012). CROSSDRESSING CINEMA: AN ANALYSIS OF TRANSGENDER.

Mulvey, L. (1975). Visual Pleasure and Narrative Cinema.

Mulvey, L. (1999). Visual Pleasure and Narrative Cinema. new york: Eds. Leo Braudy and Marshall Cohen.

Neuendorf, K. A., Gore, T. D., Dalessandro, A., Janstova, P., \& Snyder-Suhy, S. (2010). Shaken and Stirred: A Content Analysis of Women's Portrayals in James Bond Films. 62, p. 747.

Raj, K. (2014). Exploring gendered stereotypes in smoking patterns. p. 4.

Strinati, D. (2004). An Introduction to Theories of Popular Culture.

Sultana, A. (2011). Patriarchy and Women's Subordination:. 7. 